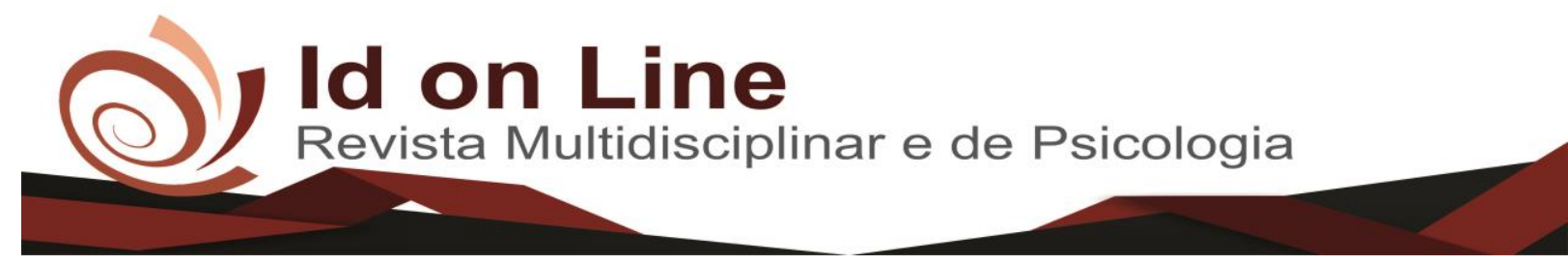

Comment

\title{
Panorama da História Sociolinguística do Brasil
}

Luiz Eduardo Simões de Burgos ${ }^{1}$; Izabel Cristina Lima Dias Alves ${ }^{2}$

Resumo: O presente artigo busca investigar a história sociolinguística do Português Brasileiro, para isso traça um panorama linguístico da língua portuguesa no Brasil a partir do descobrimento até os dias atuais, mostrando as diversas teorias sobre a constrição da língua em solo brasileiro. No estudo, também se procura observar como se processou a expansão do português popular no Brasil, bem como qual ou quais foram os agentes responsáveis por tal acontecimento, analisando, ainda, a questão da escolarização como forma de difusão do português culto.

Palavras-chave: História sociolinguística, Português Brasileiro.

\section{Sociolinguistics History Overview of Brazil}

Abstract: This article seeks to investigate the sociolinguistic history of Brazilian Portuguese, so it draws a linguistic situation of the Portuguese language in Brazil from the discovery to the present day, showing the various theories about the constriction of the language in Brazilian soil. In the study also observes how did you go about expanding the popular Portuguese in Brazil, and which or what were the agents responsible for such an event, analyzing also the issue of education as a way of spreading the Portuguese culture.

Keywords: sociolinguistics History, Brazilian Portuguese.

\section{Introdução}

Com o propósito de se retratar o perfil sociolinguístico brasileiro, será apresentado um panorama da história sociolinguística do Brasil, para tanto, observou-se desde a chegada dos portugueses em 1500 até a questão da escolaridade durante toda história linguística do país.

Vale dizer que a constituição da Língua Portuguesa no território brasileiro sofreu influência dos vários povos que aqui se encontraram e juntos produziram, constituíram o que se denomina de Português Brasileiro.

\footnotetext{
${ }^{1}$ Professor Adjunto de Língua Portuguesa da Universidade do Estado da Bahia - UNEB, Campus V - Santo Antônio de Jesus. Contato: eduardoburgos@bol.com.br

2 Professora Auxiliar de Língua Portuguesa da Universidade do Estado da Bahia - UNEB, Campus XXI - Ipiaú. Contato: icldias@uneb.br
} 
Nesta análise, também será possível verificar e entender como se processa a variação linguística que acontece no Brasil, além de se entender o papel da escolarização na heterogeneidade dialetal tanto no Português Popular Brasileiro (PPB), quanto no Português Culto (PC), como se percebem em pesquisas Sociolinguísticas observadas.

\section{O Português Brasileiro}

Há mais de quinhentos anos, na época da chegada dos portugueses, muitos e diferentes povos indígenas já habitavam o Brasil e falavam suas próprias línguas, cerca de 1.125, o que mostra que desde aquele tempo já não havia uma unidade linguística no Brasil, como muitas vezes se pensa.

Rodrigues (2000, p. 543) ressalta que os portugueses que vieram morar no Brasil, na sua grande maioria, eram homens desacompanhados de mulheres, e, por isso, passaram a conviver com mulheres indígenas e a ter filhos mestiços, os chamados mamelucos, o que não agradava à Igreja nem ao Estado. Essa situação se intensificou nos séculos XVI e XVII, porém, na área mais próxima do centro administrativo, que era Salvador, tal fato não ocorria, pois, nessa região, o número de mulheres entre os colonizadores era maior, pois eram enviadas, de Portugal, em grande quantidade, órfãs para que casassem com os portugueses. Então, pode-se dizer que a língua portuguesa se restringia a essas áreas.

Nas outras áreas, onde a miscigenação foi mais forte, os mestiços normalmente adquiriam a língua da mãe, para depois aprender, também, a língua do pai. Com o desaparecimento dos índios "puros", a língua tupi foi-se alterando e passou a ser chamada de língua geral ou nheengatu (que significa 'língua boa'). Essa língua foi o instrumento de comunicação adotado pelos portugueses para integrar a força de trabalho indígena. A língua geral também era utilizada pelos jesuítas para catequizar os índios e, assim, facilitar a conversão do gentio, tendo até sido escrita uma gramática dessa língua geral pelo Pe. Anchieta. Durante muito tempo o português e a língua geral viveram lado a lado. Observem o que diz Teyssier, citando o Pe. Vieira:

Em 1694, dizia Pe. Vieira que 'as famílias dos portugueses e índios em São Paulo estão tão ligadas hoje umas com as outras, que as mulheres e os filhos se criam mística e domesticamente, e a língua que nas ditas famílias se fala é a dos índios, e a portuguesa a vão os meninos aprender à escola’. [...]. (TEYSSIER, 1997, 94-95). 
Hoje é possível encontrar, aproximadamente 180 línguas indígenas faladas no Brasil e, segundo Lucchesi (2012, p. 51), em sua grande maioria em vias de extinção, contando apenas com algumas poucas dezenas de falantes idosos. Deve-se lembrar que a diminuição da quantidade de línguas indígenas se deve graças ao desaparecimento dos povos que as falavam, em consequência: 1) das campanhas de extermínio ou de caça para servirem de escravos, movidas pelos europeus, por seus descendentes e prepostos; 2) das epidemias de doenças contagiosas trazidas pelos colonizadores; 3) pela redução progressiva de seus territórios de caça, plantio (seus meios de subsistência); 4) pela assimilação forçada ou induzida aos costumes dos brancos. Vale lembrar que aconteceu em maior número o desaparecimento de línguas indígenas nas regiões em que a colonização se processou há mais tempo.

Apesar da diminuição da presença indígena, como consequência do contato linguístico, a língua portuguesa, falada pelos colonos, ficou fortemente marcada pelo vocabulário da língua dos índios, já que a maior parte da nomenclatura para as coisas próprias do Brasil, então, completamente desconhecidas na Europa, era designada nas línguas indígenas, tais como: espécimes da flora (abacaxi, jacarandá, aipim etc.), espécimes da fauna (capivara, paca, jacaré etc.), objetos, comidas, mitologia, moléstias, fenômenos naturais (curau, saci, cuca, catapora, pororoca etc.), expressões (chorar pitanga, andar na pindaíba, estar de tocaia etc.). Essas línguas também influenciaram a toponímia (por exemplo, Abaeté, Jequié, Murutuba etc.) e a antroponímia (por exemplo, Araci, Jacira, Iara etc.).

A língua geral entra em decadência, e, entre as razões que contribuíram para isso, destacam-se a criação do Diretório dos Índios pelo Marquês de Pombal e a chegada de numerosos imigrantes portugueses. O Diretório dos Índios era um conjunto de normas que determinavam, entre outras coisas, a proibição do uso da língua geral e obrigava o uso da língua portuguesa, além disso, expulsou do Brasil os principais protetores da língua brasílica, os jesuítas. Assim, pelo desuso, a língua geral perde status de língua comum, reduzindo-se apenas a certo número de palavras incorporadas ao léxico do português falado no Brasil e a muitos topônimos ${ }^{1}$.

Como os índios não se sujeitaram ao trabalho forçado, e, além disso, os jesuítas faziam campanhas contra a escravidão indígena, os donos de engenhos de cana-de-açúcar buscaram

\footnotetext{
${ }^{1}$ Cf. Chaves de Melo (1981, p. 43): "Um ponto em que todos estão de acordo é afirmar que imensa foi a contribuição do tupi ao vocabulário da língua portuguesa americana. Se levarmos em conta a toponímia, talvez orcem por 10.000 os vocábulos que ao português advieram da principal fonte indígena, o que constitui valiosíssimo legado.".
} 
outra fonte de mão de obra escrava para atender às necessidades. A nova força de trabalho escravo vinha da África, de onde os africanos eram sequestrados e transportados para as colônias. A presença dos escravos negros foi significativa, principalmente, nas regiões em que se concentravam as plantações de cana, algodão e fumo, principalmente, na Bahia e em Pernambuco. Segundo Lucchesi (2000, p. 46), a cultura do fumo teve um papel importante durante a escravidão, pois servia como elemento de troca no comércio de escravos. Essa cultura se desenvolveu predominantemente na Bahia, na região da cidade de Cachoeira.

Estima-se que no período da escravidão cerca de quatro milhões de africanos foram trazidos para o Brasil. Esses escravos que aqui chegavam falavam suas línguas nativas e vinham de diversas regiões da África, logicamente, vinham mais escravos dos lugares em que os portugueses controlavam as rotas, ou seja, as que passavam pelo Golfo de Guiné, e pela costa de Angola. Do Golfo de Guiné, vinham falantes de línguas da família kwa: principalmente o ewe (aqui denominado jeje) e o iorubá (aqui denominado nagô). De Angola, vinham falantes de línguas da família banto: principalmente, o quicongo, o quimbundo e o umbundo.

Vale dizer, ainda, que os escravos eram classificados em ladinos ou boçais. Os ladinos tinham certo conhecimento da língua portuguesa e, por terem tal conhecimento, gozavam de alguns privilégios. Segundo Silva Neto (1963 [1951], p. 39), os escravos ladinos já falavam um dialeto crioulo-português desde quando viviam na costa da África. Já os boçais não conheciam a língua portuguesa. Com o aumento da necessidade de manter a comunicação e a busca da ascensão social, a língua portuguesa foi se tornando a segunda língua dos africanos, pois era a língua de prestígio, a língua dos dominantes. Assim, cada vez mais, buscava-se a proficiência na nova língua.

Contudo, é preciso que se diga que a aquisição da segunda língua se processou de forma deficiente, posto que os escravos, na sua grande maioria, tinham pouco contato com os falantes nativos do português e, consequentemente, poucos acessos aos modelos da língua alvo:

\footnotetext{
A massa escrava sucessivamente para aqui trazida, desde a quarta década do século XVI até avançado o XIX, mesmo com a extinção do tráfico oficial em 1830, com suas 200/300 línguas, teve de aprender a língua dos senhores, a partir de situações precárias de exposição à língua-alvo, a portuguesa. (MATTOS E SILVA, 2004a, p. 100).
}

Essa situação contribuiu para a aprendizagem de uma variante impregnada com as marcas de suas línguas maternas e com um elevado grau de simplificação. Nesse sentido é que Chaves de Melo (1981, p. 74) ressalta que é possível perceber que as línguas africanas faladas 
pelos escravos que aqui chegaram influenciaram mais profundamente o português falado no Brasil que o tupi, pois, os negros viveram longamente em contato com o branco, falavam o idioma do branco, mesmo que simplificando a morfologia, alterando fonemas, reduzindo desinências etc:

\begin{abstract}
Estabelecida no Brasil a população escrava, constituíram-se duas 'línguas gerais' dos negros, de acordo com a procedência destes: foi o 'nagô' ou 'ioruba' na Bahia e o 'quimbundo' nas outras regiões. O 'quimbundo' é mais importante não só linguisticamente - porque tem maior poder expressivo, bem como vocabulário mais rico, - senão também e principalmente porque foi muito mais empregado, por maior número de indivíduos e numa área geográfica muito mais considerável. Porém o tanto o 'nagô' como o 'quimbundo' são línguas desprovidas de flexão. Este último faz a concordância por meio de prefixos especiais repetidos junto ao termo subordinado. Desse modo, natural seria que, adotando o português como segunda língua, imprimissem nele os africanos as marcas dos seus antigos hábito linguísticos, executando-o, não apenas como sotaque peculiar deformador, senão que também simplificando-lhe a morfologia como reduzir-lhe as flexões. (CHAVES DE MELO, 1981, p. 76).
\end{abstract}

Para esse autor, os filhos e netos dos africanos eram falantes de dialeto crioulo, tipo africano nagô ou quimbundo e que o mesmo acontecera com os descendentes dos índios, surgindo um dialeto crioulo de tipo tupi, dialetos esses, possivelmente, segundo o autor, se fundiram em alguns pontos do território nacional dando origem a um dialeto crioulo, dialeto esse do tipo tupi-quimbundo. Mais tarde, tal dialeto se lusitanizou surgindo, então, o dialeto caipira.

A polêmica sobre a origem crioula do PB vem despertando o interesse de diversos autores há mais de um século. A prova disso é que, segundo Lucchesi (2000, p.24), já nos fins do século XIX o filólogo português Adolfo Coelho procura demonstrar as semelhanças entre o PB e os crioulos de base portuguesa, sobretudo no que concerne a falta de concordância nominal e verbal.

Outros autores como Mendonça (1933) e Raimundo (1933), como informa Lucchesi (2000, p. 98), atribuíram à influência das línguas africanas à motivação de praticamente todas as características que distinguem o português europeu (PE) do PB.

Contrariamente, Silva Neto (1963 [1951]), Elia (1979), embora admitam a formação de crioulos e semicrioulos, através do contato de línguas, negam uma influência maior desse contato na constituição do $\mathrm{PB}$, graças à ideia de que o colonizador branco era membro de um povo culturalmente superior. Para Câmara Jr. (1972, 1976), a influência das línguas africanas, 
na constituição do $\mathrm{PB}$, se resumiria à aceleração de tendências prefiguradas no sistema linguístico do português, posição que já havia sido delineada por Silva Neto (1963 [1951]).

Segundo Guy (1981, 1989), o Português Popular Brasileiro (PPB) é resultante de um processo prévio de crioulização, iniciado de forma mais significativa a partir do século XVII, ao qual se seguiria um processo posterior de descrioulização, em função do prolongado contato do PPB com o português culto (PC). Discordando da posição de Guy (1981), Tarallo (1993) argumenta que os falantes do PB tendem, cada vez mais, a realizar o sujeito e apagar o objeto, enquanto que os falantes do PE, ao contrário, apagam o sujeito e realizam o objeto. Desse modo, estariam o PB e o PE se afastando, não ocorrendo, portanto, a descrioulização.

Naro e Scherre (1993) argumentam, resgatando a ideia de Câmara Jr.(1972), contrariamente à influência de processos prévios de crioulização, que não há registros históricos da estabilização de algum crioulo em solo brasileiro. E afirmam que as mudanças que afetaram a concordância nominal e verbal no Brasil teriam as suas origens, não na simplificação operada pelo contato entre línguas, mas em mudanças fonéticas iniciadas em Portugal, sob a ação das forças de uma deriva secular².

Lucchesi (1994, 1996, 1998a, 1999, 2000) e Baxter e Lucchesi (1997) aproximam-se da posição de Guy (1981), mas fazem restrições à ideia de uma crioulização plena do PPB. Por outro lado, Lucchesi (2000) salienta que o processo sócio-histórico de constituição da realidade linguística brasileira é bipolarizado, ou seja, no pólo das camadas médias e altas da sociedade brasileira, pode-se perceber, nos primeiros séculos de história do Brasil, um comportamento linguístico conservador de uma elite colonial. No pólo das camadas populares, ocorrem, desde os princípios da colonização, transformações linguísticas, decorrentes do contato, principalmente, entre as línguas africanas e o português. Esse contexto sociolinguístico, segundo Lucchesi (2000), propiciaria as condições, não para uma crioulização típica do português, mas para a ocorrência de processos de Transmissão Linguística Irregular mais leve. ${ }^{3}$.

Também sobre a questão do contato linguístico assim se manifesta Houaiss:

Parece, assim, muito provável que, independentemente, das tentativas de explicação por esta ou aquela via, dos fenômenos havidos no Brasil, houve, paralelamente, no

\footnotetext{
${ }^{2}$ cf. SAPIR, Edward. A linguagem: introdução ao estudo da fala. Trad. J. Mattoso Câmara Jr. Rio de Janeiro: Ministério da Educação e Cultura/Instituto Nacional do Livro, 1954.

${ }^{3}$ O termo Transmissão Linguística Irregular foi cunhado por Baxter e Lucchesi (1997) e desenvolvido por Lucchesi (1998a, 2000, 2001).
} 
Brasil pelo menos, a um tempo, uma tendência à crioulização e uma tendência ao incremento do português comum de base mais ou menos culturalizada. (HOUAISS, 1988, p.119).

Um aspecto relevante para entender a situação sociolinguística do Brasil atual, como afirmam Ilari e Basso (2009, p. 49), é a questão da formação do território nacional. O atual território brasileiro foi definido durante quatro séculos e se expandiu muito além do que tinha sido atribuído a Portugal pelo Tratado de Tordesilhas. Nessa expansão, novas regiões foram incorporadas graças, sobretudo, às Entradas e Bandeiras e aos grandes ciclos econômicos. Também contribuíram para a configuração do atual território brasileiro alguns acordos internacionais, como os que reconheceram: o domínio espanhol na região do Rio da Prata; a recuperação da independência do Uruguai e a incorporação do atual estado do Acre ao território brasileiro.

\begin{abstract}
Os movimentos de exploração e colonização do período colonial espalharam pelo atual território brasileiro um sem-número de aldeias e vilas cujos nomes continham, tipicamente, referências à Coroa portuguesa, aos santos da Igreja Católica e à toponímia indígena (por exemplo: Vila Real do Senhor Bom Jesus de Cuiabá, hoje Cuiabá, ou Forte do Príncipe da Beira). Embora esse processo tenha sido realizado em nome de Portugal, seus agentes não foram portugueses típicos. Nos movimentos de expansão territorial, e nos grandes ciclos econômicos que os motivaram, sempre foi preponderante a presença de índios, negros e mestiços, falantes de uma língua que não poderia ser o português lusitano, mas somente um português marcado por fortíssimas interferências das línguas indígenas e africanas. (ILARI e BASSO, 2009, p. 51).
\end{abstract}

Vale dizer que a partir do século XVIII alguns autores já relatam a percepção de traços específicos que caracterizam o português falado no Brasil, principalmente em relação a pronuncia de alguns sons. Com a vinda de cerca de 15.000 portugueses juntamente com a família real portuguesa para o Brasil em 1808, o Rio de Janeiro se torna a capital do reino e ocorre a relusitanização da cidade.

Com a independência do Brasil em 1822, o sentimento de nacionalismo estava em alta, o que provocou a valorização de tudo que distinguisse o país da sua antiga metrópole. Então, buscavam-se as raízes indígenas e se acolhiam imigrantes de outros países europeus, como alemães, italianos, etc. Os descendentes desses imigrantes se integraram à sociedade brasileira. Essa tendência de valorização das distinções entre o Brasil e sua antiga Metrópole também atingia as questões linguísticas, pois se buscava nos textos literários uma linguagem impregnada de termos genuinamente brasileiros, Nessa época, nascia a ideia de que no Brasil não se falava 
mais a língua portuguesa e sim, a língua brasileira. Mais tarde, a partir da Semana de Arte Moderna, em 1922, os escritores romperam com a tradição, com a linguagem que refletia os cânones gramaticais portugueses e passaram a usar um vocabulário popular, com construções de uso corrente pelos brasileiros, diferentemente do que se denomina de norma padrão, ou seja, aquela descrita na gramática normativa ${ }^{4}$.

Com o crescimento dos centros urbanos, o Brasil deixa de ser um país rural, a maioria de sua população concentra-se nas grandes cidades, de onde "se elabora, nos dias de hoje, a forma particular de português que é a língua do Brasil” (TEYSSIER, 1997, 97).

Mattos e Silva (2004a, p. 33) afirma que a demografia histórica e a escolarização no Brasil são dois aspectos essenciais para que se compreenda, explique e interprete a heterogeneidade dialetal que aqui se observa, tanto no que se refere, segundo a autora, à diversidade horizontal e vertical do PPB quanto no PC, aparentemente homogêneo, mas, vale dizer, que tal aparência já vem mudando, pois as pesquisas realizadas com falantes cultos mostram que o PC também se apresenta heterogêneo.

A autora chama a atenção para o fato de que as demografias históricas são sempre aproximativas e não apresentam quadros exatos como os recenseamentos atuais. Essa autora informa, ainda, que a primeira estimativa demográfica foi realizada pelo Pe. Anchieta em 1575, o qual verificou que no Brasil uma população de 57.000 habitantes nas últimas décadas do século XVI. Nesse censo, a soma de índios e negros apresentou um total de 32.000 pessoas, ou seja, mais da metade da população. Então, fica claro que a população européia era a minoria em terras brasileiras.

Mattos e Silva (2004a, p. 126) diz que, desde o período colonial (século XVI) até a época da Independência do Brasil (século XIX), predominam etnias não brancas. A população não branca atingia uma média de $70 \%$ contra $30 \%$ da etnia branca, que até a metade do século XIX era representada quase exclusivamente pelos portugueses e lusos descendentes. Os índios integrados, portanto, os contáveis, decresceram, no início da colonização de $50 \%$ para $2 \%$ na

\footnotetext{
${ }^{4}$ Cf. Bortoni-Ricardo (2005, p. 35): "Chamamos de língua oficial a descrita na gramática normativa. Do fato de se basear em escritores não contemporâneos resulta o seu distanciamento, em muitos pontos, da realidade linguística oral e literária no Brasil. Detentora, porém, do beneplácito do sistema sociopolítico, que a considera correta em detrimento de todas as outras variedades, impõe-se o seu emprego em documentos oficiais e formais, bem como o seu estudo na escola, onde o professor ensina, embora ele próprio não a use em sua fala coloquial.". 
metade do século XIX. Já a população negra, entre os séculos XVII ao XIX, apresentava um percentual de $60 \%$ da população. Observem a Tabela $1^{5}$ :

Tabela 1: Demografia histórica do Brasil do século XVI até o século XIX.

\begin{tabular}{lccccc}
\hline & $1538-1600$ & $1601-1700$ & $1701-1800$ & $1801-1850$ & $1851-1890$ \\
\hline Africanos & $20 \%$ & $30 \%$ & $20 \%$ & $12 \%$ & $2 \%$ \\
Negros brasileiros & - & $20 \%$ & $21 \%$ & $19 \%$ & $13 \%$ \\
Mulatos & - & $10 \%$ & $19 \%$ & $34 \%$ & $42 \%$ \\
Brancos brasileiros & - & $5 \%$ & $10 \%$ & $17 \%$ & $24 \%$ \\
Europeus & $30 \%$ & $25 \%$ & $22 \%$ & $14 \%$ & $17 \%$ \\
Indios integrados & $50 \%$ & $10 \%$ & $8 \%$ & $4 \%$ & $2 \%$ \\
\hline
\end{tabular}

Fonte: Mattos e Silva (2004a, p. 101)

A partir dos dados observados, Mattos e Silva (2004a, p. 102) afirma que se admite serem os africanos e afro-descendentes fortes candidatos para a difusão do vernáculo ou português popular, que, como assinala a autora, é a variante sociolinguística mais generalizada no Brasil. A autora alerta para o fato de que o tráfico de escravos africanos no Brasil estava vinculado à demanda de mão de obra e, portanto, concentravam-se nas grandes frentes de exploração econômica do processo colonial. Desse modo, o percurso da escravidão brasileira passa pelas lavouras canavieiras da Bahia, Pernambuco, Rio de Janeiro; pela mineração de ouro, diamantes, em Minas Gerais, Mato Grosso, Goiás; pela lavoura de algodão no Maranhão; pelas charqueadas do Rio Grande do Sul. Vale dizer que, com a proibição do tráfico oficial, intensificou-se a migração interna de escravos o que, logicamente, permitia a difusão da língua por eles falada. Observem o que diz Pessoa de Castro sobre a migração escrava:

Finalmente, com a extinção do tráfico transatlântico para o Brasil, de 1853 a 1888 , ano da abolição da escravatura no país, o tráfico interno foi intensificado, ou seja, escravos negros das plantações do nordeste foram levados para outras nas regiões do sul e sudeste (depois ocupadas por imigrantes europeus e asiáticos, calculados, hoje, em mais de sete milhões) e, em direção oposta, do centro-oeste para a floresta amazônica onde os povos indígenas são predominantes. Sabe-se, por exemplo, que a população escrava da Bahia passou de 500.000 para menos de 180.000 em 1894, com uma média anual, entre 1850-60, de 5.195 indivíduos exportados principalmente para os mercados do Rio de Janeiro e São Paulo, que pagavam por eles qualquer preço, como ocorreu nas regiões de mineração durante o século XVIII. (PESSOA DE CASTRO, 2001, p. 64).

5 A Tabela 1 foi extraída de Mussa (1991) apud Mattos e Silva (2004, p. 101). 
Ainda falando sobre a demografia histórica, não se pode deixar de salientar a presença de imigrantes europeus e asiáticos. Ilari e Basso (2009, p. 80) afirmam que chegaram ao Brasil a partir de 1820 e atingindo seu ápice de 1890 até 1930 quase quatro milhões de imigrantes, dentre esses, estavam, além de portugueses, principalmente, italianos, espanhóis, alemães, japoneses, árabes, turcos. Também sobre os imigrantes que vieram para o Brasil Mattos e Silva assinala:

[...] Na sua grande maioria, esses novos componentes étnicos e linguísticos da sociedade brasileira vão se localizar de São Paulo para o Sul e, também na sua grande maioria, se integraram, no princípio, em propriedades rurais e como trabalhadores urbanos, inserindo-se nas camadas mais baixas da sociedade brasileira. Adquiriram eles também, no princípio, o português na oralidade e sem o controle normativo da escola. (MATTOS E SILVA, 2004a, p. 128-129).

Nessa linha de pensamento, Ilari e Basso (2009, p. 80) informam que, de início, o Estado brasileiro não encarou como problema o fato de os filhos dos imigrantes nascidos aqui no Brasil terem como língua vernácula a língua de seus pais e a prevalência dessas nas comunidades em que viviam. Muitos desses lugares evoluíram e formaram-se vilas e cidades, as quais recebiam nomes na língua dos imigrantes. Só mais tarde, em função da participação de imigrantes em revoltas e a Segunda Guerra Mundial é que o Estado passa a adotar medidas para limitar o uso de línguas estrangeiras no território brasileiro, tendo, inclusive, proibido que se alfabetizasse em outra língua que não fosse o português. Também várias cidades fundadas e nomeadas em línguas de imigrantes foram rebatizadas com nomes da língua portuguesa.

Os autores assinalam que da convivência do PB com as línguas dos imigrantes europeus e asiáticos permitiu-se a incorporação de vocábulos provenientes dessas línguas que hoje já estão correntes no português falado no Brasil, porém, salientam os autores, que tais influências exercidas são quase nulas na sintaxe e na morfologia. Observem o que dizem os autores:

\footnotetext{
Abundantes no vocabulário do português brasileiro, as influências das línguas dos imigrantes são quase nulas na morfologia, e na sintaxe, e isso tem uma explicação fácil de adivinhar: quando as línguas dos imigrantes europeus chegaram aqui, o português do Brasil já era uma língua muito estandardizada e gramatizada. (ILARI e BASSO, 2009, p. 82). (grifos dos autores).
}

Quanto à questão da escolarização, Mattos e Silva (2004a, p. 99) diz que o PC sofreu a difusão a partir da escolarização mais alta e liga-se mais ao PE, sendo mais europeizado. Apesar 
disso, é preciso ressaltar que, como afirma Bagno (2003, p. 96), a história da Educação no Brasil é mais um fator que explica por que é muito restrita a apropriação da norma-padrão. Isto pode ser entendido levando-se em conta, por exemplo, que somente em 1827 é fundada a Faculdade de Direito de São Paulo, primeira instituição superior no Brasil. Esse autor salienta, ainda, que se se comparar as colonizações portuguesas e espanholas se verá que na América espanhola em 1538 já se tinha implantada a Universidade de Santo Domingo, e no final da colonização espanhola, contava-se com vinte e três universidades. Além disso, destaca ainda esse autor, que somente em 1808 tem início a indústria gráfica no Brasil, que se transformaria numa indústria editorial quase um século e meio depois.

Como se sabe, desde o início da colonização até a sua expulsão, pela Lei do Diretório dos Índios, foram os jesuítas os educadores no Brasil. Houaiss (1988, p. 147) diz que a escolarização não jesuítica se fez a partir dos meados do século XVIII em uma mínima parte da população. Somente os filhos das famílias mais ricas iam estudar nas universidades de Portugal.

\begin{abstract}
O ensino das primeiras letras foi precário até adentro do século XX, até 1920. A tradição literária, isso não bastante, oferece obras de ficção e poesia exemplares quanto ao cuidado com que se acompanhavam os estudos das crianças e jovens. Mas trata-se de uma tradição criada pelos próprios escritores. Se se parte da muito provável hipótese de que, por 1800, os letrados (isto é, literatados) no Brasil seriam 0,5\% da população e se chega a 1920 com $20-30 \%$, vê-se que o seu número absoluto aumentou continuamente, pelo aumento do percentual e da população (3,5-4 milhões a 25-30 milhões). (HOUAISS, 1988, p. 148).
\end{abstract}

As taxas de analfabetismo no Brasil têm caído nas últimas décadas, porém os índices ainda são altos se comparados a países desenvolvidos. E os índices ficam mais elevados ainda se for observada, por exemplo, a região Nordeste, na qual, segundo os dados colhidos do Censo de 2010, o percentual de analfabetos chega a $28 \%$ nas cidades com até 50 mil habitantes. Vale salientar que nessas cidades a proporção de idosos analfabetos é de $60 \%$, entre os jovens de 15 a 24 anos tem-se um percentual de 4,9\%, quase o dobro do percentual nacional que é de 2,5\%. Observem a Tabela 02 que demonstra a diminuição do índice de analfabetismo nas últimas décadas, apesar de o percentual ainda ser alto se se comparar com os índices obtidos nos países desenvolvidos. 
Tabela 02: População a partir de 15 anos

\begin{tabular}{ccc}
\hline ANO & ANALFABETOS & \% ANALFABETOS \\
\hline 1950 & 15.272 .000 & $50,6 \%$ \\
1960 & 15.964 .000 & $39,7 \%$ \\
1970 & 18.100 .000 & $33,7 \%$ \\
1980 & 19.356 .000 & $25,9 \%$ \\
1990 & 17.733 .000 & $18,4 \%$ \\
2000 & 16.294 .889 & $13,63 \%$ \\
2010 & 13.933 .173 & $9,6 \%$ \\
\hline
\end{tabular}

Fonte: IBGE, Censos Demográficos.

Por outro lado, com base nos dados da Tabela 02, é possível inferir que é crescente o contato de um maior número de falantes com a norma culta, o que vem corroborar com o postulado por Lucchesi (1994, 1998a, 2001, 2002 e 2006) quanto à questão da bipolarização do português brasileiro. ( $c f$. item 2.2).

\section{Considerações Finais}

Diante de tudo que foi exposto, é inegável que o contato linguístico no Brasil aconteceu desde o primeiro momento em que os componentes da esquadra de Cabral aqui chegaram, e, desse momento em diante, iniciou-se uma troca linguística incessante entre os colonizadores europeus, os povos indígenas e os povos que aqui chegaram. Dessa troca de influência linguística, formou-se o PB falado. Porém, deve-se ressaltar que, dentre todos os povos vindos para o Brasil, destacam-se os africanos. Eles vieram em grande quantidade, tendo o número de seus membros superado o de brancos e índios, portanto, é natural que tenham uma influência significativa na constituição do PB falado, produzindo, assim, inovações, as quais se impregnaram na língua e que hoje já se incorporaram ao falar do povo, faltando apenas que, muitas delas, sejam aceitas como padrão. 


\section{Referências}

BAXTER, Alan. e LUCCHESI, Dante. A relevância dos processos de pidginização e crioulização na formação da língua portuguesa no Brasil. Revista Estudos Linguísticos e Literários, n.19, p.65-84, mar, 1997.

BURGOS, Luiz Eduardo Simões de. A variação na concordância verbal no português popular do município de Cachoeira-BA. 2015.182f. Tese (Doutorado em Língua e Cultura) - Instituto de Letras, Universidade Federal da Bahia, Salvador.

CENSO DO IBGE (2010). Disponível em: <http://www.ibge.gov.br/home/ estatistica/populacao/censo2010/resultados_dou/BA2010.pdf>. Acesso em 15. outubro. 2013.

CHAVES DE MELO, Gladstone. A língua do Brasil. 4. ed. Rio de Janeiro: Padrão, 1981.

ELIA, Sílvio. A unidade linguística do Brasil. Rio de Janeiro: Padrão, 1979.

FARACO, Carlos Alberto. Linguística histórica: uma introdução ao estudo da história das línguas. 2.ed. São Paulo: Parábola, 2007.

FARACO, Carlos Alberto. Norma culta brasileira: desatando alguns nós. 2.ed. São Paulo: Parábola, 2009.

HOUAISS, Antonio. O português do Brasil. 2. ed. Rio de Janeiro: Unibrade, 1988.

ILARI, Rodolfo e BASSO, Renato. O português da gente: a língua que estudamos, a língua que falamos. 2.ed. São Paulo: Contexto, 2009.

LUCCHESI, Dante. Variação e norma: elementos para uma caracterização sociolinguística do português do Brasil. Revista Internacional de Língua Portuguesa, n. 12, p. 17-28, 1994.

LUCCHESI, Dante. Variação, mudança e norma: a questão brasileira. In: CARDOSO, S.A.M. (Org.). Diversidade, linguística e ensino. Salvador: EDUFBA, 1996.

LUCCHESI, Dante. A constituição histórica do português brasileiro como um processo bipolarizado: tendências atuais de mudança nas normas culta e popular. In: GRO $\beta E$, S.; ZIMMERMANN, K. (Eds.) "Substandard" e mudança no português do Brasil. Frankfurt am Main: TFM. 1998a.

LUCCHESI, Dante. Sistema, mudança e linguagem: um percurso da linguística neste século. Lisboa: Colibri, 1998b.

LUCCHESI, Dante. A variação na concordância de gênero em dialetos despidginizantes e descrioulizantes do português do Brasil. In: ZIMMERMANN, K. (Ed.). Lenguas criollas de base lexical española y portuguesa. Madrid: Ibero- Americana, 1999. 
LUCCHESI, Dante. A variação na concordância de gênero em uma comunidade de fala afrobrasileira: novos elementos sobre a formação do português do Brasil. 2000. 364 f. Tese (Doutorado em Linguística) - Universidade Federal do Rio de Janeiro, Rio de Janeiro.

LUCCHESI, Dante. As duas grandes vertentes da história sociolinguística do Brasil (15002000) (The two great trends of Brazilian Sociolinguistic history (1500-2000). Revista D. E. L. T. A., n. 17, p. 97-130, jan. 2001.

LUCCHESI, Dante. Norma linguística e realidade social. IN: BAGNO, Marcos. (org.) Linguística da norma. São Paulo: Loyola, 2002.

LUCCHESI, Dante. Parâmetros sociolingüísticos do português brasileiro. Revista da ABRALIN, v.5, n.1 e 2, p.83-112, 2006.

LUCCHESI, Dante e BAXTER, Alan. A transmissão linguística Irregular. In: LUCCHESI, Dante.: BAXTER, Alan.: RIBEIRO, Ilza. (orgs.) O português afro-brasileiro. Salvador: EDUFBA, 2009.

LUCCHESI, Dante. A diferenciação da língua portuguesa no Brasil e o contato entre línguas. In: Estudos de Lingüística Galega, Santiago de Compostela, n. 4, julho de 2012, p. 45-65. Disponível em: http://ilg.usc.es/elg/volume/4/\#PESCUDA.

MATTOS E SILVA, Rosa Virgínia. Ensaios para uma sócio-história do português brasileiro. São Paulo: Parábola, 2004a.

MATTOS E SILVA, Rosa Virgínia. "O português são dois..." novas fronteiras, velhos problemas. São Paulo: Parábola, 2004b.

MENDONÇA, Renato. A influência africana no português do Brasil. Rio de Janeiro: Sauer, 1933.

PESSOA DE CASTRO, Yeda. Falares africanos na Bahia: um vocabulário afro-brasileiro. Rio de Janeiro: Academia Brasileira de Letras/Topbooks, 2001.

RAIMUNDO, Jacques. O elemento afro-negro na língua portuguesa. Rio de Janeiro: Renascença, 1933

RODRIGUES, Aryon Dall'Igna. Língua brasileiras: para o conhecimento das línguas indígenas.São Paulo: Loyola, 1986.

RODRIGUES, Aryon Dall'Igna. Breve história da língua dos índios vistos por Cabral. Revista Universa. Brasília, v. 8, nº 3, p. 541-55, 2000.

SILVA NETO, Serafim. Introdução ao estudo da língua portuguesa no Brasil. 2. ed. Rio de Janeiro: INL, 1963 [1951]. 
TEYSSIER, Paul. História da língua portuguesa. Trad. Celso Cunha. São Paulo: Martins Fontes, 1997.

\section{Como citar este artigo (Formato ABNT):}

BURGOS, Luiz Eduardo Simões de; ALVES, Izabel Cristina L. D. Panorama da História Sociolinguística do Brasil. Id on Line Rev.Mult. Psic., 2018, vol.12, n.40, p.367-381. ISSN: 19811179 .

Recebido: 04/04/2018

Aceito 05/04/2018 